\title{
La elección del sexo
}

\author{
$X X Y \mid$ Lucía Puenzo | 2007 \\ Margarita Alvarez Villanueva* \\ Escuela Lacaniana de Psicoanálisis, Barcelona, España
}

Recibido: 07 de junio 2016; aprobado: 13 de julio 2016

\begin{abstract}
Resumen
$X X Y$, es una película dramática de la cineasta argentina Lucía Puenzo, la cual trata de la historia de Alex, una adolescente de quince años, quien está afectada por su condición de intersexualidad. El presente trabajo aborda, a partir del análisis de esta película, la cuestión de la elección de sexo desde la perspectiva del psicoanálisis de la orientación lacaniana, entendiéndose en tanto una elección de goce.
\end{abstract}

Palabras clave: Elección de sexo | Sexuación | Goce | Intersexualidad

The sex's choice

\begin{abstract}
$X X Y$, is a dramatic film from the Argentinian filmmaker Lucia Puenzo, which is the story of Alex, a teenager of fifteen years old, who is affected by their intersex condition. This paper shows, from the analysis of this film, the issue of sex selection from the perspective of psychoanalysis of the Lacanian orientation, understood as a choice of jouissance.
\end{abstract}

Keywords: Sex choice | Sexuation | Jouissance | Intersexuality

XXY (Puenzo, 2007), es una película de la cineasta argentina Lucía Puenzo, responsable también del guion que está basado en un cuento de Sergio Bizzio. Es un film inteligente, sensible, intenso e inquietante. Estrenado en el año 2007, ganó el premio Semana de la Crítica del Festival de Cannes y el Goya a la mejor película extranjera de habla hispana del mismo año.

De entrada, quiero resaltar algo que parecería obvio: no es un caso real, es una ficción. Pero, lo subrayo, porque hay una confusión entre el título y el contenido de la película: confunde un individuo afectado por una alteración cromosómica XXY, también conocida como "síndrome de Klinefelter", con un caso de intersexualidad. No es lo mismo y voy a explicarlo brevemente.

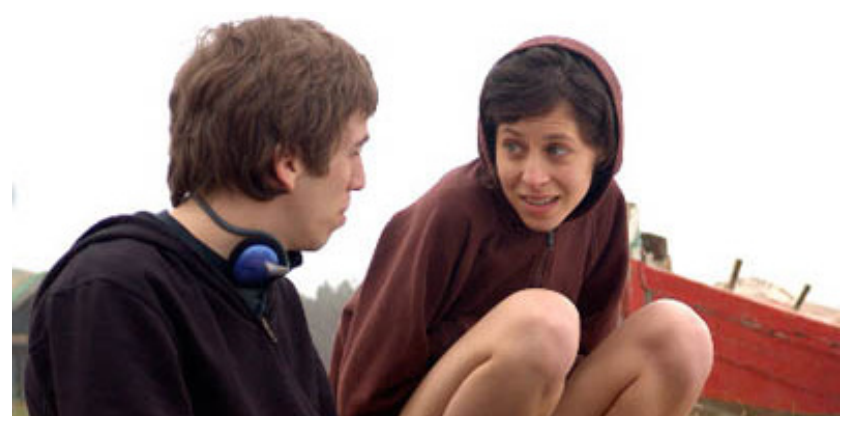

El sexo anatómico está determinado por la presencia de los cromosomas sexuales XY en el varón, y los cromosomas sexuales XX en la mujer. Un individuo XXY es alguien que ha nacido anatómicamente varón pero que presenta un hipogonadismo, es decir un disfuncionamiento de las gónadas sexuales masculinas, lo que produce una producción menor de testosterona que puede reflejarse, según el individuo, y según el grado, en cierta feminización de los rasgos o del aspecto: por ejemplo, crecimiento de las mamas, poca presencia de vello corporal -el cual sigue además un patrón de distribución femenino-, una mayor cantidad de grasa corporal, por ejemplo en las caderas, y en algunos casos problemas de fertilidad en la vida adulta. Así, la cuestión afecta a los llamados caracteres sexuales secundarios, no a los caracteres sexuales primarios u órganos genitales propiamente dichos. Un intersexual, sin embargo, es un individuo que nace con caracteres sexuales primarios de los dos sexos, más o menos definidos según el caso, lo cual no quiere decir que, en ningún caso, ambos sean funcionales. En muchos de ellos, esta presencia de los dos órganos no es visible en el momento del nacimiento, ya que los testículos por ejemplo están retraídos y no se hacen evidentes

m.alvarezvillanueva@gmail.com 
hasta la pubertad o la vida adulta -conocemos el célebre caso de Herculine Barbin del siglo XIX, cuyas memorias publicó Michel Foucault (Foucault, 2007), considerado anatómicamente mujer y llamado por el nombre de Alexine hasta la edad adulta, nombre que hace resonar el de Alex la protagonista de nuestra película-.

Una vez aclarada esta confusión entre los individuos XXY y los intersexuales a la que induce el título, quiero señalar que eso no resta ningún valor a la película: en ella la ficción se va tejiendo con sensibilidad e inteligencia cerniendo el real del que se trata, el real del sexo, como nos da la pista el libro El origen del sexo que la protagonista va leyendo a lo largo de la película. Luego, nos enteramos de que se lo ha dado su padre, biólogo, con la esperanza de que ella pueda extraer de allí un saber sobre lo que le pasa. Por supuesto, el saber biológico no dice nada sobre el goce, que es el real del sexo en juego para el psicoanálisis. Y que, más allá de la cuestión de la intersexualidad, es la cuestión que está en juego en la historia.

Esa es mi lectura.

Seguidamente voy a hacer un resumen de la película, señalando algunas cuestiones que me parecen interesantes, tal como la elección de sexo.

\section{La elección del sexo}

Aunque el secreto recorre el film, poco a poco se va develando que Alex, la adolescente de quince años en torno a la cual gira el nudo del drama, está afectada por su condición de intersexualidad.

Al nacer -explican- se le diagnosticó una hiperplasia suprarrenal, la cual genera una producción mayor de andrógenos, una hormona sexual que da características masculinas. Ella es la causa común de uno de los tipos de intersexualidad, conocida como la $46 \mathrm{XX}$, en la que tanto el nivel de hormonas femeninas como la constitución de los órganos reproductores femeninos son correctos, pero los órganos sexuales suelen experimentar un crecimiento inusual, lo que les hace parecer un pene - sin llegar a serlo-. Por lo que dicen, el caso de Alex podría ser así, aunque la ficción la presenta "con las dos cosas". Al nacer, los médicos recomendaron operar a Alex pero el padre se negó a hacerlo. Para él, Alex era "una niña perfecta”.

Él y su mujer, partieron de Buenos Aires a un pueblo tranquilo de la costa uruguaya para que Alex pudiera crecer libre, tanto de los prejuicios, como de las presiones sociales y médicas hasta que algún día, con ellos, pudiera elegir el sexo con el que quería vivir. Voy a detenerme un momento en esta cuestión.

Desde que los avances de la medicina han permitido una cirugía sexual más o menos "fina” de los intersexuales, muchos de ellos son sometidos de entrada a operaciones, a veces desde su detección en la época fetal mediante intervenciones intrauterinas.

En muchos casos, son los propios médicos los que han elegido el sexo del niño después de hacerle estudios cromosómicos, hormonales y anatómicos para determinar qué genitales pueden ser menos ambiguos o más funcionales. En otros casos, han sido, o son, los padres. El hecho de querer avanzar la operación lo más posible se defiende con el argumento de "normalizar" lo antes posible al niño para que no tenga "problemas".

Sin embargo, esta cuestión ha generado, con razón, numerosos debates éticos, poniendo en cuestión el hecho de que otros decidan el sexo propio. La tendencia actual es que sean los propios intersexuales los que decidan operarse, o no, por lo que se intenta retrasar el mayor tiempo posible la toma de decisión, hasta que el sujeto tenga elementos o criterios suficientes para ello.

Esto sería más consonante con la teoría psicoanalítica de la sexuación. Para el psicoanálisis, el sexo siempre nos viene asignado por el Otro. Tal y como señala Lacan en el Seminario ... ou pire (Lacan, 2012), cuando introduce los tres pasos de la sexuación, es el Otro quien nos reconoce primero como niños o niñas incluso desde la primeras ecografías, en base a una "pequeña diferencia", la presencia o ausencia de pene. Pero esa observación nunca es un dato primero aunque lo parezca: la presencia-ausencia de un rasgo convierten esa observación en una lectura significante.

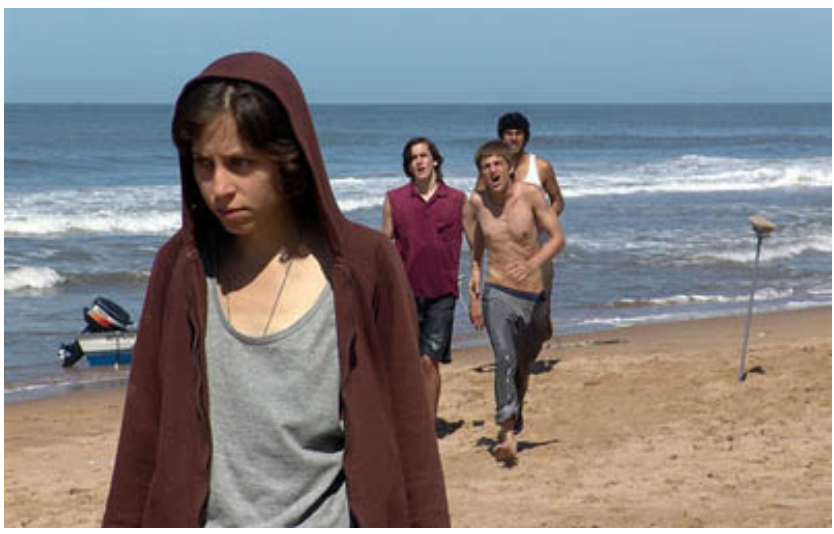

El segundo paso es que esa lectura nunca va a ser meramente objetiva sino que va estar contaminada, de forma explícita o entre líneas, por la ideología de lo que quiere decir ser hombre o ser mujer para el Otro en 
cuestión - sean los padres o el Otro social, el Otro de la época-, o lo que es lo mismo, por el fantasma. Es una interpretación fantasmática que el niño recibe junto con esta primera asignación del sexo por parte del adulto.

Lacan formula un tercer paso: la decisión última de situarse del lado femenino o masculino no va a ser del Otro sino del niño, en base a una identificación de su goce, es decir, más allá de la anatomía, de la asignación de sexo del Otro registrada por el Estado, de las identificaciones simbólico-imaginarias o del género. Un sujeto no necesita pensarse como mujer o estar inscrito en el registro civil para gozar de un modo masculino o femenino: todo fálico o no-todo fálico.

Lo habitual es que haya cierta discordancia entre la anatomía, las identificaciones, el goce, que no todo encaje perfectamente, que haya contradicciones, porque la sexualidad humana no es natural, es decir, instintiva: está adulterada porque el niño se ve inmerso al nacer en un mundo simbólico, es decir, en el lenguaje. El Otro que recibe al niño es otro que habla. Sin embargo, en algunos casos, por ejemplo en la transexualidad, el sujeto quiere eliminar esa discordancia (Wedekin, 2013).

En el intersexual, podemos decir que la tendencia es que sea el Otro quien de entrada quiera eliminarla: quiera determinar el sexo más adecuado pensando que ello resolverá la cuestión de la sexuación.

Si se deja elegir al sujeto, no es seguro, pero hay la posibilidad de que él haga una elección que conlleva un elemento distinto de los criterios anatómicos o médicos, de las identificaciones simbólico-imaginarias. El sujeto entonces puede confrontarse no solo a su anatomía y a sus identificaciones sino, también, a su goce real. Esto último es muy claro en la película.

El proceso de virilización de los caracteres sexuales que padece Alex, consecuencia de su hiperplasia, se acentúa con la pubertad y debe tomar corticoides para evitar, por ejemplo, la aparición de la barba. Sin embargo, ella ha decidido dejar de tomarlos hace quince días, lo que inquieta a sus padres, a cada uno de manera distinta.

La madre quiere someterla a una operación para que le "quiten lo que le sobra para que siga siendo una mujer". Por esa razón ha llamado a un cirujano conocido de Buenos Aires, interesado en el caso, que ha venido aparentemente de visita con su mujer y su hijo Álvaro, un adolescente un poco mayor que Alex. No ha contado ni a su marido ni a Alex, el motivo real de la visita pero ellos, poco a poco, lo descubren. Y, el padre, entonces, se opone a la operación: "Sabíamos que iba a pasar-dice a la madre- no iba a poder ser mujer toda la vida”.
Ambos, padre y madre, coinciden en querer decidir rápidamente: que sea mujer o que sea hombre, es decir, eliminar las dudas o la discordancia. La madre quiere que Alex evite la virilización de los caracteres sexuales secundarios con medicación y se deje extirpar lo que "le sobra" para que siga siendo una mujer -ella solo quería tener hijas por lo que la virilización aparente de Alex la pone delante de un duelo-; el padre reconociendo que Alex ya no es la "niña perfecta", por esa misma virilización, y aceptándolo.

Pero los dos se equivocan en los criterios que consideran importantes para tomar una decisión. Ser hombre o mujer no tiene que ver con la anatomía, ni con las identificaciones a los roles sexuales tipificados en cada cultura, ni con la conducta. Feminidad o masculinidad son elecciones de goce, inconscientes.

Encontrarse con el goce propio y situarse en relación a ello siempre es traumático, siempre faltan las palabras para decirlo.

El drama de la pubertad no es otra cosa. Es el mismo drama que escribe Wedekind hace casi ciento veinte años en El Despertar de la primavera (Wedekind, 2013): el acceso a la sexualidad para cualquier adolescente, en tanto exige confrontarse a un goce y posicionarse respecto a él, nunca es algo tranquilo, ni rápido, ni sin consecuencias. Requiere un tiempo para ver, un tiempo para comprender y un tiempo para concluir.

Para Alex, también. Ni para ella ni para los otros dos adolescentes de la película, Álvaro y Wando, será fácil. Como en la obra de Wedekind, vemos tres adolescentes divididos respecto a su goce, no compartido ni compartible, singular en cada uno.

Alex necesita tiempo. Los padres quieren que todo se solucione rápido, concluir de una vez, es decir, cerrar la cuestión de si tienen un hijo o si tienen una hija, evitar la angustia. Pero Alex aún no ha concluido. Porque la cuestión fundamental que ha de resolver no es cómo situarse respecto al propio cuerpo ni ante el Otro, sino cómo situarse respecto al propio goce.

En el caso de Alex, la metamorfosis de su cuerpo -en el sentido de una virilización- sin duda añade una complicación especial a lo que Freud llamó la metamorfosis de la pubertad, que es la metamorfosis que introduce en la relación del sujeto con el cuerpo la irrupción, no de las hormonas, sino del goce propio, siempre Otro. La intersexualidad complejiza el drama de la adolescencia donde se juega esta partida.

Alex hace un pasaje al acto: penetra a Álvaro -el hijo del cirujano-de manera agresiva e imprevista cuando éste 
piensa que está teniendo relaciones con una mujer - por lo que este último queda consternado por lo ocurrido, dividido por la irrupción de un goce nuevo-. Por otro lado, Alex se enamora de Wando, con el que según parece tenía cierta intimidad especial, pero esta relación fue rechazada al percatarse Wando de su intersexualidad. Dice Alex: "Nunca pensé que me fuera a enamorar de alguien".

Alex no solo está dividida en relación a lo que el otro espera de él, su madre, su padre, los médicos, el pueblo. Fundamentalmente aparece dividida entre la niña que siempre ha sido y lo que presentifica de pregunta el goce de su órgano. Aparece dividida entre su goce fálico y el amor por un hombre, que la rechaza.

Pero ¿no es en general ese, la división entre el amor y el goce, el drama del amor en el que todos debemos iniciarnos? Ese drama no se resuelve en la película. No es una película tranquilizadora o "rosa". Toca lo real. Es inquietante.

Sin embargo, Alex puede dar finalmente una respuesta a sus padres: "No quiero operaciones, ni pastillas ni cambios de colegio". Esto quiere decir que no va a operarse, que no va a ir contra la virilización de su cuerpo sino que acepta las modificaciones de su cuerpo y asume que tendrá que hacer con lo que eso suponga para el Otro y para ella. ¿O tendríamos que decir "para él”?

El Otro demanda a Alex que decida si es hombre o mujer, y ella, se niega a dicha categorización. Se pregunta: “¿Por qué tendría que decidirse por una cosa o por otra? Soy las dos cosas". Y, ahí, se equivoca.

Es cierto que Lacan sitúa que la categorización hombre - mujer se nos escapa a cada instante (Lacan, 2012, p. 176). Nadie podría rellenar todos los ítems que pretenden definir lo que esas categorías representan idealmente. En eso, el psicoanálisis está de acuerdo con Alex, y también con los transgeneristas o los teóricos queer.

Sin embargo, el psicoanálisis no considera que el entrar o no en las categorías sexuales de hombre y mujer, sea un obstáculo para que el sujeto entre en la categorización fálica, femenino y masculino, es decir, que haga una elección de goce todo fálico o no todo fálico. Y, desde ese punto de vista, parece que Alex ya ha elegido.

\section{Referencias}

Álvarez, M. (2014) “La pasión transexual: convicción o certeza”. Freudiana. Revista de Psicoanálisis de la ELP-Catalunya. Número 71. Barcelona: Comunidad de Catalunya ELP.

Ansermet, F. (2002) “El psicoanalista frente a la prevención perinatal”. Revista El Niño. Número 10. Barcelona: ICF.

Foucault, M. (2007). Herculine Barbin llamada Alexina B. Madrid: Talasa.

Lacan, J. (1971-1972 [2012]) “...ou pire” en El seminario de Jacques Lacan. Libro 19. Buenos Aires: Paidós.

Lacan, J. (1972-73 [2008]). “Aún” en El seminario de Jacques Lacan Libro 20. Buenos Aires: Paidós.

Miller, J-A. (2008). El partenaire-sintoma. Buenos Aires: Paidós.

Wedekind, F. (2013). El despertar de la primavera. Buenos Aires: Letra Viva. 